\title{
Entre lo policial y lo bélico: \\ las transformaciones de las dimensiones de las fuerzas policiales de Lima (1827-1838)
}

\section{Between police work and warfare:}

transformations in the scope of Lima's police forces (1827-1838)

\section{Carlos Jesús Ríos Rodríguez ${ }^{1}$}

Universidad Nacional Mayor de San Marcos. Lima, Perú

carlosr2892@gmail.com

ORCID 0000-0003-3098-5608

Citar como: Ríos, C. (2020). Entre la función policial y los campos de batalla: las transformaciones de las dimensiones de las fuerzas policiales de Lima (1827-1838). Desde el Sur, 12(1), pp. 57-78.

\section{RESUMEN}

El objetivo principal de este artículo es examinar la formación del Estado peruano a través del análisis de las cambiantes dimensiones cuantitativas de las fuerzas policiales del Ejército destinadas al departamento de Lima durante los primeros años de la era republicana. Se plantea que dichas fuerzas policiales eran debilitadas o suprimidas en contextos bélicos para incorporar sus efectivos a las tropas de los caudillos que se alistaban a marchar a los campos de batalla, lo que demuestra que en el Perú las guerras debilitaban la capacidad coercitiva estatal vinculada a la seguridad pública durante la temprana república.

\section{PALABRAS CLAVE}

Fuerzas policiales, Ejército, Estado, seguridad pública, Lima, Perú

\section{ABSTRACT}

The main aim of this article is to examine the formation of the Peruvian state through analysis of the shifting quantitative dimensions of the army's police forces assigned to

1 Licenciado en Historia por la Universidad Nacional Federico Villarreal, y magíster en Historia por la Universidad Nacional Mayor de San Marcos. Actualmente es docente de esta universidad. 
the department of Lima during the first years of the republican era. It can be argued that those police forces were weakened or suppressed in the context of war in order to incorporate their personnel into the forces of the caudillos who were preparing to march onto the battlefields, thereby demonstrating that in Peru wars weakened the state's coercive capacity with regard to public security during the early republican period.

\section{KEYWORDS}

Police force, army, state, public security, Lima, Peru

\section{Introducción}

La seguridad pública fue una cuestión primordial para las autoridades de la temprana república peruana. En 1826, en un pronunciamiento oficial, se dejó claro que la «seguridad pública» era «el bien primario e inapreciable que espera todo hombre de la sociedad en que vive y a que tiene incuestionable derecho [...] desvelándose el Gobierno por evitar que no se turbe por los malhechores, y que las propiedades y personas, reposen a cubierto de ataques y violencia en poblado y en el campo» (Oviedo, 1861 [1826], tomo 6, p. 294). Sin embargo, nueve años después, a fines de 1835 , las fuerzas policiales fueron sacadas de la ciudad de Lima para ser incorporadas al ejército del caudillo Felipe Santiago Salaverry. Esto provocó que la ciudad quedara desguarnecida y que el montonero León Escobar y sus huestes ingresaran a saquearla (Basadre, 2015, tomo 2, pp. 106-107). El contraste entre este hecho y la concepción de la seguridad pública que tenían las autoridades, mencionada líneas arriba, evidencia la accidentada formación del Estado peruano. Por ello, para comprender este proceso histórico resulta pertinente analizar la formación de las fuerzas policiales en el Perú de la temprana república.

En este artículo nos centraremos en examinar las cambiantes dimensiones cuantitativas de la tropa de las fuerzas policiales del Ejército destinadas al departamento de Lima entre 1827 -año a partir del cual contamos con cifras mensuales-y 1838. Cabe precisar que una parte de este periodo está marcada por un estado de guerra permanente que se inicia en 1834 y que provocó, junto con otros factores, la fundación de la Confederación Perú-Boliviana en 1836, unidad política que subsistió hasta inicios de 1839.

¿Cómo podemos comprender la formación de los Estados modernos? El concepto de Estado moderno acuñado por Max Weber es una herramienta teórica que es citada usualmente en las investigaciones sobre la 
formación de los Estados. Para este autor, como es bien sabido, los Estados modernos son instituciones que monopolizan el ejercicio de la coacción física legal dentro de un determinado territorio (Weber, 2002, p. 1056). No obstante, consideramos que el uso de este concepto es problemático, pues plantea un tipo ideal que puede oscurecer nuestra comprensión de las particularidades de los procesos de formación de los Estados. Por ello, proponemos más bien que es mucho más operativo asumir la formación de los Estados modernos como procesos históricos en los que una estructura institucional de gobierno busca consolidar su hegemonía sobre el resto de la sociedad, y se apoya, en gran medida, en el uso de la violencia comúnmente a través de instituciones como el Ejército o las fuerzas policiales.

Para el caso del Perú, siguiendo la perspectiva que hemos planteado, podemos afirmar, en líneas generales, que el proceso de formación del Estado moderno se inicia aproximadamente a fines del siglo XVIII, cuando la monarquía española decide formar y mantener un ejército permanente en dicho territorio como consecuencia de la rebelión de Túpac Amaru (Fisher, 2000, p. 82). Es decir, el proceso de formación del Estado en el Perú tuvo varias décadas de retraso en comparación con Europa. En este continente dicho proceso empezó alrededor del siglo XVI, con la formación de ejército permanentes (Mackenney, 1996, pp. 102-103). Por lo tanto, cabe precisar que el dominio colonial de la monarquía española se pudo consolidar en el Perú sin la necesidad de mantener grandes ejércitos.

La construcción del Estado peruano no fue una tarea fácil durante la temprana república. La sociedad tenía recursos considerables para contrarrestar su accionar. Uno de estos recursos fue el armamento de guerra que se dispersó entre la población producto de las guerras de independencia (Velásquez, 2013, pp. 407-408), lo que provocó la proliferación del bandolerismo y el aumento de su peligrosidad (Walker, 1990, pp. 107-119). Además, los presidentes no podían controlar la totalidad del ejército. Esta fuerza armada fue dividida por pugnas internas, que, a su vez, generaron una serie de guerras civiles que marcaron la historia de la temprana república peruana. Inscrito dentro de este complejo proceso de formación del Estado se encuentra la construcción de las fuerzas policiales del Ejército.

Son sumamente escasos los trabajos acerca de la formación de fuerzas policiales en América Latina durante la temprana república. Para el caso peruano se ha abordado la formación de fuerzas policiales en dicho periodo desde un enfoque que privilegia la descripción de la normatividad (Zapata Cesti, 1949; Merino Arana, 1966). Para el caso chileno y mexicano, en cambio, en los últimos años han aparecido trabajos que no solo privilegian el análisis de la normatividad de las fuerzas policiales, sino también 
su funcionamiento (Palma Alvarado, 2016; Pulido Esteva, 2017). En ese sentido, este trabajo pretende llamar la atención sobre la pertinencia del estudio de la formación de las fuerzas policiales para entender el complejo proceso de construcción de los Estados latinoamericanos.

Ahora bien, en este artículo se plantea que en contextos bélicos las fuerzas policiales del Ejército eran debilitadas o suprimidas para reforzar a las tropas que se alistaban a marchar a los campos de batalla. En 1834 y 1835 la dinámica bélica, así como la precariedad del ejército, agravada por su división en bandos enfrentados en guerras civiles, provocaron el debilitamiento y la supresión de las fuerzas policiales. En 1838, en cambio, en un contexto de fortalecimiento del ejército, el desarrollo de la guerra en Lima generó la participación de la fuerza policial en el campo de bataIla, su disolución y su posterior reactivación, aunque con una dimensión mucho menor a la que había tenido a inicios de dicho año.

En el desarrollo de esta investigación se han consultado varios tipos de fuentes. En el Archivo General de la Nación se revisaron las listas de revista de las fuerzas policiales, documentación enviada al Ministerio de Hacienda con el fin de que se paguen los sueldos de los efectivos policiales. Este tipo de fuente nos ha permitido conocer las cambiantes dimensiones de las fuerzas policiales del Ejército. Asimismo, se consultaron las Constituciones promulgadas durante la temprana república, que se encuentran en el Archivo Digital de la Legislación Peruana, y la normatividad recogida en la colección compilada por Juan Oviedo entre 1861 y 1865, para comprender el origen y la normatividad de dichas fuerzas policiales. Por último, se ha revisado la correspondencia enviada por la Prefectura de Lima y los comandantes de las fuerzas policiales al Ministerio de Guerra y Marina, documentación que se encuentra en el Archivo Histórico Militar, para entender el funcionamiento de dichas fuerzas policiales y complementar la información de las mencionadas fuentes.

\section{Las fuerzas policiales del Ejército: origen y normatividad}

La caída del gobierno colonial en Lima ocasionó una crisis de la seguridad pública. La salida del ejército realista de la ciudad el 5 de julio de 1821 provocó que este mismo día ocurriera el saqueo de un gran número de locales comerciales (Flores Galindo, 1991, p. 171). La entrada del ejército independentista no implicó una mejora considerable de la situación. El inicio de la guerra de independencia provocó que un gran contingente de armas de guerra se dispersara entre la población de todos los sectores sociales (Velásquez, 2013, pp. 408-409). Este factor agravó el estado de la seguridad pública. José de San Martín, comandante general del ejército independentista, fue consciente de ello: 
La multitud de robos y toda especie de crímenes que se están cometiendo en esta heroica capital por algunas partidas de hombres que a influjo de las pasadas ocurrencias fueron tolerados y armados en su defensa, cuya criminal conducta borrando cualquier servicio que hubiesen prestado, se hacen acreedores a mi indignación y a la de todos los hombres, exige imperiosamente todo mi cuidado en precaverlos, pues nada más anhelo que la tranquilidad fraternal de todos los habitantes de este nuevo Estado (Oviedo, 1861 [1821], tomo 6, p. 290).

Antes de la llegada del ejército independentista liderado por San Martín, el bandolerismo en los caminos de la costa se había tornado endémico (Flores Galindo, 1991, p. 111). Sin embargo, el armamento empleado por los bandoleros era sumamente precario. Comúnmente «portaban unos sables hechos por ellos mismos con hojas viejas y mohosas, dientes en los filos y una improvisada abrazadera» (Flores Galindo, 1991, p. 115). No obstante, la dispersión de armas de fuego producto de las guerras de independencia alteró este panorama social. La posesión de carabinas o fusiles dotaba a los bandidos de una mayor peligrosidad que la que habían tenido anteriormente, y provocó que en 1822 los caminos cercanos a la ciudad de Lima estuvieran plagados de «multitud de malhechores» que podían «influir en el menoscabo de la fuerza armada» (Oviedo, 1861 [1823], tomo 6, p. 291).

El Congreso Constituyente, inaugurado en 1822, buscó solucionar el problema del bandolerismo. Ello se evidenció en la Constitución de 1823. En su artículo 165 se estableció que debía existir una guardia de policía independiente del ejército. Esta fuerza policial, de acuerdo con el artículo 171, debía «proteger la seguridad privada, purgando los caminos de malhechores, y persiguiendo a los delincuentes con sujeción a las órdenes de la autoridad respectiva». En ese sentido, la fundación de dicha fuerza policial era una forma de retribuir a la sociedad «la parte que le toca en el sostén de las cargas públicas» (Oviedo, 1861 [1826], tomo 6, p. 294). Es decir, para las autoridades del naciente Estado peruano la formación de fuerzas policiales era una forma de legitimar su autoridad y, por ende, su capacidad de recaudar impuestos.

La participación del ejército en la formación de fuerzas policiales fue un fenómeno generalizado en el mundo atlántico hasta mediados del siglo XIX (Tilly, 1992, p. 58). El Perú no fue ajeno a dicha tendencia, a pesar de lo que estableció la Constitución de 1823. En 1827 se estableció que la fuerza policial encargada de custodiar los caminos del departamento de Lima debía ser formada por el Estado Mayor del Ejército (Oviedo, 1861 [1827], tomo 6, p. 294). En la Constitución de 1828 ello quedó claro. En el artículo 145 se estableció que una de las funciones del Ejército era 
«asegurar el orden interior». Por ello, la injerencia del Ejército en la formación de dicha fuerza policial demuestra que para las autoridades de la naciente república la seguridad pública era considerada una parte esencial del mantenimiento del orden interno.

Sin embargo, el Ejército no tenía el control absoluto de la fuerza policial que formaba. En 1827 se dejó claro que el prefecto del departamento de Lima era el «jefe superior» de dicha fuerza policial, lo que implicaba que también estaba a cargo de su organización interna. Al Ejército, en cambio, solo le correspondía «formar» la fuerza policial, es decir, proveer al prefecto de los hombres que la integrarían. El Ministerio de Hacienda, por su parte, tenía que encargarse del pago de los salarios (Oviedo, 1861 [1827], tomo 6, p. 294). Este diseño institucional encajaba, en gran medida, con lo planteado en las Constituciones de 1823 y 1826, y las promulgadas posteriormente dentro de nuestro marco temporal, en 1828 y 1834 . En estas Constituciones se estableció que los prefectos, funcionarios nombrados por el Poder Ejecutivo, eran los responsables, entre otras funciones, de la conservación del orden y la seguridad pública de los departamentos, unidades territoriales en las que se había dividido la naciente república. En ese sentido, el prefecto de Lima estaba encargado de destinar la fuerza policial no solo a la ciudad capital y a los caminos cercanos a ella, sino también a los caminos que cruzaban las demás provincias que integraban el departamento a su cargo: Ica, Cañete, Chancay, Santa, Canta, Yauyos, Huarochirí y el puerto del Callao.

Por otro lado, cabe añadir que se estableció que las municipalidades no debían tener ninguna injerencia en la organización de las fuerzas policiales. En el reglamento de municipalidades de 1828 se dejó claro que la seguridad pública era una tarea exclusiva del Poder Ejecutivo (Oviedo, 1861 [1828], tomo 2, p. 373). Esta medida le restaba capacidad de presión a los notables de Lima en cuanto a la formación y el desenvolvimiento de las fuerzas policiales del Ejército. El Poder Ejecutivo, representado por el prefecto, obtenía así un gran margen de maniobra en relación con el uso de las fuerzas policiales.

Ahora bien, en junio de 1834, durante el gobierno de Luis José de Orbegoso, el prefecto Francisco Valle Riestra solicitó al Consejo de Estado que se creara una compañía de policía independiente del Ejército, debido a que el «número de malhechores se ha aumentado considerablemente, y los pacíficos ciudadanos son asaltados en los caminos, y aún en sus propios hogares» (Oviedo, 1861 [1834], tomo 6, p. 300).

Luciano Cano, secretario del Consejo de Estado, informó a Matías León, ministro de Gobierno, que la respuesta del Consejo buscaría evitar 
dos «extremos» dañinos para el Estado y la población. El primero consistía en establecer que efectivos del Ejército se encargaran de la seguridad pública, tal como había estado ocurriendo hasta esta fecha. A pesar de que las compañías del Ejército eran «las más propias para desempeñar con buen éxito las comisiones que se encargan a la fuerza de policía», el Consejo reconocía que no podían cumplir estas funciones de manera eficiente porque su «continua movilidad» provocaba que carecieran «de las nociones prácticas de la topografía de cada pueblo, ignoran los medios de subsistencia de las diversas clases que los componen, desconocen los hábitos viciosos que induciendo al contagio de una moral corrompida atacan la seguridad individual y turban el orden público». Es decir, la no especialización del Ejército en la tarea de la seguridad pública era un impedimento clave para que la desempeñasen con eficiencia.

El segundo extremo era aumentar el número de la tropa y, por lo tanto, violar la ley del 1 de setiembre de 1831, que establecía que el Ejército no debía superar el número de 3000 efectivos. En ese sentido, «los nombres no hacen las cosas». Es decir, aumentar la tropa conllevaba también gastos en salarios, entrenamiento, alimentación y armamento. Además, se originaría una «escandalosa inseguridad de propiedades y de vida a presencia de un numeroso ejército que no tiene todas las calidades necesarias para desempeñar esta clase de servicio». En otras palabras, el incremento del ejército provocaría que se enrolaran muchos individuos con antecedentes delictivos (Oviedo, 1861 [1834], tomo 6, pp. 300-301).

Finalmente, el Consejo de Estado decretó en julio de 1834 la fundación del Cuerpo de Policía, una nueva fuerza policial separada del Ejército; es decir, sus efectivos ya no serían contados como parte de su fuerza efectiva. Esta nueva fuerza debía estar integrada por dos compañías, una de infantería y otra de caballería, integradas por 60 y 50 efectivos, respectivamente. La primera de ellas tenía que ser destinada a la ciudad capital, y la segunda, al campo del departamento (Oviedo, 1861 [1834], tomo 6, pp. 299-300). La cifra total de integrantes de la reformada fuerza policial no significaba un gran incremento de las dimensiones que en años anteriores tuvieron las fuerzas policiales del Ejército, como explicaremos más adelante. Este reducido incremento se explica principalmente por la pobreza de la hacienda pública. Los recursos fiscales eran insuficientes para cubrir las necesidades del Estado (Contreras, 2012, pp. 45-46), lo que originaba que este se hallara constantemente en estado de quiebra (Gootenberg, 1997, p. 189). En otras palabras, el déficit fiscal fue una constante durante los primeros años de la era republicana (Seminario, 2015, p. 825).

La reforma de 1834 no implicó que la prefectura dejase de encargarse de la dirección de la fuerza policial del Ejército (Oviedo, 1861 [1834], 
tomo 6, pp. 299-300). Sin embargo, su organización interna pasó a ser una función de la Inspección General del Ejército. Es decir, el Ejército ya no solo tenía que encargarse de proveer de hombres a la fuerza policial de Lima, sino también de su «disciplina, arreglo y demás propio de su constitución militar» (Oviedo, 1861 [1834], tomo 6, p. 307), de modo que así obtenía la capacidad de reducir sus dimensiones para fortalecer a otras compañías del Ejército, a pesar de que los efectivos policiales ya no eran contados como parte de su fuerza efectiva. Por ello, la reforma de 1834 no significó una solución al problema de la porosidad entre la fuerza policial del Ejército y el resto de compañías que integraban esta fuerza armada, fenómeno que generaba el debilitamiento de dicho cuerpo policial a fin de fortalecer a las compañías que se alistaban a marchar a la guerra como analizaremos más adelante.

Antes de la reforma de 1834, la caballería fue el tipo de estructura militar que mejor se amoldaba al objetivo principal de la fuerza policial del Ejército: la persecución de bandidos en los caminos. Las características de la caballería eran propicias para perseguir a los salteadores en espacios abiertos, y, por ende, atacar y retroceder rápidamente. Además, los bandidos cometían sus delitos comúnmente a caballo, y estaban armados con carabinas y sables (Tschudi, 1968 [1846], p. 172), armamento similar con el que contaba el escuadrón, compuesto básicamente por tercerolas, pistolas, sables y lanzas (Medina, 1989, p. 251).

Sin embargo, la reforma de 1834, al incluir la creación de una infantería de policía, estableció que la protección de la ciudad capital era también una prioridad de la fuerza policial del Ejército. Las autoridades buscaban mantener permanentemente un contingente de esta fuerza policial en la ciudad capital. De esta manera, se buscaba evitar el ingreso de montoneros a esta urbe en contextos de guerra civil (Ríos, 2018, pp. 60-71). Las montoneras fueron guerrillas ajenas al ejército regular, que tuvieron una importante participación en las guerras que marcaron la historia del Perú durante la temprana república (Méndez, 2013, pp. 390-391). Parte de los montoneros eran reclutados por los caudillos entre los «salteadores de caminos e individuos culpables de otros delitos» (Tschudi, 1968 [1946], p. 177). Es decir, existía una delgada línea entre las acciones guerrilleras, la rapiña y el pillaje. Por ello, el mayor temor de la población de Lima fue que grupos de montoneros ingresasen en la ciudad. En ese sentido, la creación de la infantería de policía buscaba evitar que este gran temor se hiciese realidad. No obstante, cabe precisar que en años anteriores a 1834 era común que una parte de la fuerza policial del Ejército se mantuviera permanentemente dentro de la ciudad (Ríos, 2018, pp. 60-68). De manera que la creación de la infantería de policía significó en la práctica 
un reforzamiento de la presencia permanente que la fuerza policial del Ejército ya tenía en la ciudad.

La creación de la Confederación Perú-Boliviana trajo consigo inicialmente una reestructuración de la fuerza policial del Ejército. En octubre de 1836, el mismo mes de la creación de dicha unidad política, se ordenó que la compañía de caballería absorbiera a la de infantería ${ }^{2}$. Sin embargo, en agosto de 1837 se dispuso que nuevamente se dotara a la fuerza policial del Ejército de una compañía de infantería ${ }^{3}$. La fuerte presunción del advenimiento de una guerra por parte de las autoridades fue, en gran medida, la causa de ello, como analizaremos en el siguiente apartado. Este presentimiento finalmente fue cierto, y la guerra que se desarrolló impactaría en las dimensiones de las fuerzas policiales del Ejército como había ocurrido anteriormente.

\section{Las cambiantes dimensiones de las fuerzas policiales del Ejército}

Los primeros años de la temprana república en el departamento de Lima estuvieron marcados por la crisis de la seguridad pública. En 1828 el prefecto Manuel Ferreyros sintetizó la magnitud de dicha crisis:

el territorio de la villa de Chancay hasta el referido pueblo [de Pativilca] se halla sembrado de malhechores armados, y desertores de los cuerpos del Ejército por el fundado temor que les asiste. Agregada esta noticia a las muchas que tiene la Prefectura de los excesos que impunemente cometen los bandidos en el valle de Chancay, juzgo de mi deber representar al supremo gobierno que si no se toma oportunamente una medida enérgica y vigorosa para la persecución de los malhechores, de día en día, se irán aumentando al extremo que esta horda de salteadores se convierta en una partida o compañía armada, que no solo hará intransitable el camino por los robos y asesinatos que cometan, sino que amargará a la tranquilidad pública en las poblaciones ${ }^{4}$.

En ese sentido, para Ferreyros solo una acción decidida del Estado podía ser capaz de erradicar el bandolerismo que azotaba los caminos del departamento. Esta acción debía ser evidentemente el fortalecimiento de la fuerza policial.

2 Archivo Histórico Militar (AHM), correspondencia recibida por el Ministerio de Guerra (CRMG), 1836, Legajo (leg.) 13, documento (doc.) 233, folio (fol.) 1.

3 AHM, CRMG, 1837, leg. 1, doc. 114, fol. 1 .

4 AHM, CRMG, 1828, leg. 9, doc. 32, fols. 1-1v. 
TABLA 1. Cifras de integrantes de la tropa de las fuerzas policiales del Ejército (1827-1834)*

\begin{tabular}{lccccccccc}
\hline Enero & 1827 & 1828 & 1829 & 1830 & 1831 & 1832 & 1833 & 1834 \\
\hline Febrero & 106 & 245 & 205 & 57 & 86 & - & 96 & - \\
\hline Marzo & 95 & 273 & 207 & 58 & 100 & - & 96 & - \\
\hline Abril & - & 251 & 216 & 57 & 94 & - & 96 & 43 \\
\hline Mayo & 87 & 240 & 185 & 57 & 94 & - & 97 & 68 \\
\hline Junio & 88 & 192 & 187 & 57 & 91 & - & 97 & 62 \\
\hline Julio & 81 & 192 & - & 57 & 85 & - & 98 & 73 \\
\hline Agosto & 70 & 225 & - & 57 & 84 & - & 100 & - \\
\hline Setiembre & 88 & 197 & - & 57 & 88 & - & 100 & - \\
\hline Octubre & 76 & 200 & - & 67 & 89 & - & 100 & - \\
\hline Noviembre & 96 & 194 & - & 80 & 85 & - & 90 & - \\
\hline Diciembre & 223 & 221 & - & 80 & 80 & - & 95 & - \\
\hline
\end{tabular}

*No disponemos de cifras para 1832.

Fuentes: Archivo General de la Nación (AGN), Ministerio de Hacienda. 1827: 0. L 108, caja 89, docs. 1650-1672, 1828: 0. L. 178, caja 108, docs. 1148-1187; 1829: 0. L. 189, caja 129, docs. 927-936; 1830: 0. L. 200, caja 158, docs. 1963-1984; 1831: 0. L. 210, caja 185, docs. 1458-1489; 1833: 0. L. 227, caja 234, docs. 876-887; 1834: 0. L. 285, caja 265, docs. 1238-124.

Entre 1827 y mediados de 1829, periodo que corresponde en gran parte al gobierno de José de La Mar, el Escuadrón de Dragones de Policía fue la fuerza policial de Ejército. Durante gran parte de 1827, el número total de sus integrantes se mantuvo en niveles homogéneos. Esta tendencia se alteró a partir de diciembre de este año, como se muestra en la tabla 1, cuando el número de integrantes del escuadrón empezó a superar los 200 y a aproximarse a los 250, incluso superando esta cifra en marzo y abril de 1828. Este incremento fue la respuesta del gobierno a la crisis de seguridad que se había consolidado y agravado durante 1827 en los caminos del departamento de Lima.

Por lo tanto, el fortalecimiento del escuadrón llevado a cabo a inicios de 1828 representaba un esfuerzo por parte del Poder Ejecutivo para solucionar el problema descrito por Ferreyros. Este incremento fue posible, además, debido a que el Ejército tenía un número de integrantes muy superior al que tendría años después. En 1827 solamente la infantería tuvo aproximadamente 10800 efectivos (Piérola, 1827, p. 109).

No obstante, la guerra contra la Gran Colombia provocó que partir de junio de 1828 el total de integrantes del escuadrón se redujera ligeramente. Es decir, ya no se igualaron los niveles que se alcanzaron a inicios de 
dicho año. En la tabla 1 se evidencia que el total de efectivos de la tropa osciló entre 190 y 220 . En ese sentido, la tercera sección del escuadrón empezó a estar compuesta permanentemente por 30 integrantes a partir de octubre (Ríos, 2018, p. 41). El tamaño del Ejército durante dicho año provocó que la reducción de la fuerza policial no fuera de gran magnitud.

Si bien los enfrentamientos militares finalizaron a inicios de 1829, el Ejército peruano se mantuvo cerca de la frontera con la Gran Colombia (Basadre, 2015, tomo 1, p. 293). Por lo tanto, en los primeros meses de 1829 no se alteraron significativamente las dimensiones de la fuerza policial de Lima. Esta situación iba a cambiar radicalmente cuando el presidente La Mar fue derrocado en junio de 1829 por Agustín Gamarra, cuyo gobierno se prolongó hasta 1833. Este caudillo tuvo como uno de sus principales objetivos reducir el tamaño del Ejército. Esto fue evidente desde mediados de 1829, inmediatamente después del derrocamiento de La Mar, cuando se ordenó que gran parte del escuadrón de policía se uniera al Regimiento Lanceros del Cusco ${ }^{5}$. En consecuencia, lo que quedó del escuadrón como una unidad militar independiente pasó a llamarse Compañía de Seguridad Pública ${ }^{6}$.

En ese sentido, el 21 de setiembre de 1831 se promulgó una ley que establecía que la «fuerza numérica, total y absoluta del Ejército de la República en tiempo de paz, será la de 3000 hombres de toda arma; y la del tiempo de guerra, la que a propuesta del Ejecutivo determine el Congreso según las circunstancias» (Oviedo, 1865 [1829], tomo 13, p. 49). En octubre de 1829, el vicepresidente José Rivadeneira había dejado claras las razones que tenía el gobierno para reducir el número de efectivos del Ejército:

atendiendo a que ya está sancionada la paz con la República de Colombia, y a que es necesario economizar los inmensos gastos que gravitan sobre el erario, a causa de la excesiva fuerza que ha sido necesario mantener sobre las armas para atender a la defensa del suelo patrio: no queriendo, por otra parte, gravar con nuevas pensiones e impuestos a unos pueblos que desde luego deben sentir el benéfico influjo de la paz, después de tantos y tan repetidos sacrificios como han prestado para conservar su independencia y libertad (Oviedo, 1865 [1829], tomo 13, p. 44).

Es decir, para el gobierno de Gamarra, la paz conseguida con la Gran Colombia y la crisis de la hacienda pública motivaban la reducción del Ejército. Además, con esta medida Gamarra pudo pretender la reducción de las posibilidades de levantamientos militares en su contra. Al disminuir 
el número de efectivos del Ejército, buscaba debilitar las bases de apoyo de los caudillos rivales. Sin embargo, si esta fue su intención, no dio resultado, ya que durante su gobierno abortó 17 conspiraciones en su contra (Basadre, 2015, tomo 2, p. 56).

Las dimensiones de la Compañía de Seguridad Pública fueron sumamente inferiores a las que tuvo el escuadrón de policía en años anteriores. La reducción del Ejército impidió que la compañía tuviese un volumen similar al que tuvo el escuadrón de policía en años anteriores. En ese sentido, en 1830 el número de integrantes de la tropa de la compañía fue sumamente reducido. Por ello, la comandancia de la compañía y la prefectura exigían constantemente un incremento de la tropa ${ }^{7}$. En consecuencia, la cantidad de los integrantes de la tropa creció ligeramente en los años siguientes y el número total de efectivos osciló comúnmente entre los 85 y los 100 en 1831 y 1833, como se demuestra en la tabla 1. La ausencia de guerras durante el gobierno de Gamarra permitió esta estabilidad.

Ahora bien, a inicios de 1834 se disolvió la fuerza policial de Lima para fortalecer al ejército leal al presidente Orbegoso, el cual necesitaba ser fortalecido para derrotar al ejército del caudillo rebelde Pedro Bermúdez. Por ello, no contamos con cifras para febrero y marzo. La guerra terminó en abril, y en este mismo mes se restableció la compañía policial, la cual había sido anexada al Escuadrón Defensores de la Ley8

¿Cómo entender la supresión de la fuerza policial de Lima? La clave se encuentra en la debilidad del Ejército. Recordemos que Gamarra redujo el Ejército a 3000 efectivos. Por ello, para Orbegoso era urgente fortalecer rápidamente a las tropas leales a su gobierno que iban a marchar al campo de batalla, ya que la guerra civil había dividido al Ejército y, por ende, el número de hombres disponibles era mucho menor. Por lo tanto, una de las soluciones a este problema, que se podía aplicar de forma rápida, fue la incorporación de la totalidad de efectivos de la fuerza policial de Lima al ejército leal al presidente. Además, otros factores permitieron que esta medida se llevase a cabo. Bermúdez carecía de apoyo popular (Basadre, 2015, tomo 2, pp.70-74), y los grupos de montoneros que se encontraban dentro del departamento de Lima eran aliados de Orbegoso (Echenique, 1952, pp. 52-53). Por lo tanto, estos factores permitían percibir que no existía posibilidad alguna de que la ciudad de Lima sufriera acciones de saqueo o pillaje por parte de los montoneros mientras durara la ausencia de la fuerza policial del Ejército. 
TABLA 2. Cifras de integrantes de la tropa de las fuerzas policiales del Ejército (1835-1838)

\begin{tabular}{lllll} 
& 1835 & 1836 & 1837 & 1838 \\
\hline Enero & 110 & 54 & 102 & 215 \\
\hline Febrero & 130 & 35 & 110 & 224 \\
\hline Marzo & 41 & 87 & 102 & 226 \\
\hline Abril & 19 & 79 & 118 & 289 \\
\hline Mayo & 62 & 98 & 114 & 316 \\
\hline Junio & 50 & 94 & 140 & 327 \\
\hline Julio & 56 & 87 & 148 & 367 \\
\hline Agosto & 30 & 98 & 147 & - \\
\hline Setiembre & 95 & 88 & 238 & 69 \\
\hline Octubre & 105 & 91 & 254 & - \\
\hline Noviembre & 123 & - & 264 & 50 \\
\hline Diciembre & - & 94 & 271 & 59 \\
\hline
\end{tabular}

Fuentes: AGN, Ministerio de Hacienda. 1835: 0. L. 243, caja 290, docs. 1085-1091, 1099-1104, 1149-1152; 1836: 0. L. 249, caja 311, docs. 497-508; 1837: 0. L. 257, caja 435-449; 1838: 0. L. 266, caja 334, docs. 675-685.

Ahora bien, la compañía policial fue reformada en julio de 1834, como ya hemos analizado en el anterior apartado. El renovado Cuerpo de Policía empezó a operar recién en noviembre de este año (Oviedo, 1861 [1834], tomo 6, p. 307). Sin embargo, tal como fue concebido por Orbegoso y sus funcionarios, solo subsistió hasta febrero de 1835. La causa de ello fue la autoproclamación a fines de este mes del general Felipe Santiago Salaverry como jefe supremo de la República, lo cual dio inicio a una guerra civil entre este caudillo y Orbegoso, quien había viajado al sur del país. Poco tiempo después, Salaverry reformó la mencionada fuerza policial del departamento de Lima9 ${ }^{9}$ La dividió en dos escuadrones independientes: el Escuadrón de Dragones de Lima y el Escuadrón de Gendarmes.

La dinámica bélica tornó borrosas las fronteras entre la guerra y la custodia de la seguridad pública en las acciones del bando comandado por Salaverry. Durante gran parte de 1835, grupos de montoneros aliados a Orbegoso, entre los que se encontraban también conocidos salteadores de caminos, llevaron a cabo incursiones contra las haciendas del departamento de Lima y el ejército de Salaverry que se encontraba afuera de las murallas de la ciudad capital (Walker, 1990, pp. 121-127). La participación

9 Salaverry tenía el control político del departamento de Lima y del norte del país (Aljovín, 2000, p. 60). 
de bandidos dentro de los grupos de montoneros significaba que existía una gran posibilidad de que se llevaran a cabo saqueos dentro de la ciudad si estos grupos lograban entrar a su interior.

Las cifras que disponemos muestran que las dimensiones de los escuadrones de policía eran sumamente cambiantes. Por ejemplo, el escuadrón de gendarmes pasó de tener 19 efectivos en abril a tener 58 en mayo y 30 en agosto $^{10}$. Esto evidencia constantes traslados de efectivos a las compañías militares que eran enviadas a reprimir a los montoneros en las localidades en las que provocaban más daños ${ }^{11}$. Es decir, los escuadrones de policía no eran las únicas compañías encargadas de combatirlos, ya que, como hemos mencionado líneas arriba, las fronteras entre la guerra y la custodia de la seguridad pública se habían diluido.

En una de las expediciones llevadas a cabo para combatir a los montoneros, durante setiembre de 1835, se perdió al Escuadrón de Gendarmes, el cual fue exterminado o se pasó al bando de Orbegoso:

Como la necesidad de sostener el orden público, que fue amenazado por las montoneras que divagaban por los valles, cruzaban los caminos, y hasta se introducían a la capital, exigiese otra clase de medidas, se vio el supremo gobierno en el caso de adoptarlas, haciendo uso ese ministerio de diversas partidas compuestas también por los gendarmes. Desde entonces ya no tuvo conocimiento la Prefectura ni de su fuerza ni de su estado, y solo disponía de la pequeña que quedaba en su cuartel para la ejecución de las providencias de la Subprefectura, y auxilio que pedían los jueces, tribunales, y oficinas para el cumplimiento de las suyas, como un orden establecido para conservar la armonía de las operaciones de los diversos poderes. Últimamente ha quedado disuelto el expresado escuadrón de gendarmes ${ }^{12}$.

Por lo tanto, el escuadrón de dragones quedó como la única fuerza policial del departamento de Lima y en la práctica como la única guarnición presente en la ciudad de Lima ${ }^{13}$. Por ello, los datos de la tabla 2 para setiembre y noviembre demuestran que en estos meses las dimensiones de dicho escuadrón crecieron constantemente para reforzar la protección de la ciudad y disuadir el acercamiento de los montoneros. Sin embargo, en diciembre Salaverry decidió sacar a los efectivos policiales de la ciudad para conducirlos al sur del país y reforzar a su ejército, el cual se alistaba para enfrentarse al ejército de Orbegoso y al de su aliado Andrés Santa Cruz, presidente de Bolivia. En consecuencia, la ciudad quedó sin fuerzas

10 AGN, Ministerio de Hacienda. 1835: O. L. 243, caja 290, docs. 1085-1091.

11 AHM, CRMG, 1835, leg. 13, doc. 82, fol. 1.

12 AHM, CRMG, 1835, leg. 14, doc. 183, fols. 1-1v.

13 AHM, CRMG, 1835, leg. 14, doc. 183, fol. 1v. 
policiales, y el 28 de diciembre de 1835 el montonero y bandido León Escobar y sus huestes entraron a la ciudad de Lima. El gran temor de la población de la ciudad capital se hizo realidad. El historiador Jorge Basadre lo relata de la siguiente manera:

Al emprender el jefe supremo [Salaverry] la campaña decisiva en el sur, mientras los montoneros pululaban en los alrededores de la capital y al avanzar las tropas de Orbegoso, la capital quedó a merced de unos y otras, pues se llevó hasta los hombres encargados de la policía.

Lima vivió entonces horas de angustia que estuvieron entre las peores que sufrió bajo la anarquía durante el siglo XIX [...].

Durante la noche del 27 de diciembre hubo robo y desórdenes en los portales de la plaza de Armas. El 28 entró a Lima el montonero León Escobar acompañado por sus secuaces. Se produjeron saqueos y algunas muertes. El 29 llegó otra montonera proveniente de Huarochirí encabezada por el indio Vivas. León Escobar, entre otras fechorías, hizo un robo de consideración en el domicilio del arzobispo Jorge Benavente, y según el general Francisco de Vidal en sus memorias, intimó a los miembros de la municipalidad para que desocupasen los asientos, pues los montoneros debían ocuparlos. El 30 de diciembre, llamado por el Consejo, llegó este jefe con sus tropas, hizo llamar a León Escobar, que, en apariencia, era su correligionario político y ordenó su inmediato fusilamiento (Basadre, 2015, tomo 2, pp. 106-107).

La decisión de Salaverry debe entenderse tomando en cuenta el contexto bélico. Salaverry había trasladado parte de su ejército al sur del país pocos meses atrás, y lo que quedaba de su ejército en el departamento y en la ciudad capital estaba expuesto a un ataque combinado de los montoneros y del ejército de Orbegoso (Basadre, 2015, tomo 2, p. 106). Por ello, prefirió retirar los efectivos que tenía dentro de la ciudad y unirlos al resto de su ejército. Las consecuencias de este acto evidenciaron el grave impacto que podían tener las guerras para la seguridad de los habitantes de la ciudad capital durante la temprana república.

En enero de 1836 Orbegoso y su ejército entraron a la ciudad capital y retomaron el control de toda la provincia (Basadre, 2015, tomo 2, p. 107). Una de las consecuencias de ello fue que se restableció la fuerza policial en Lima en este mismo mes, lo que demostró, una vez más, que los caudillos consideraban que la formación de fuerzas policiales era una forma de reforzar la legitimidad de sus gobiernos. La derrota del ejército de Salaverry, en febrero de 1836, permitió que a partir del mes siguiente se trasladaran efectivos que habían participado en el desarrollo de la guerra en sur del país a la tropa de la fuerza policial de Lima. En consecuencia, en marzo la tropa se incrementó y mantuvo dimensiones homogéneas el resto del año, como se muestra en la tabla 2. 
Durante gran parte de los dos años siguientes la dimensión de la fuerza policial de Lima se incrementó considerablemente, como indica la tabla 2. En enero de 1837 su tropa superó los 100 efectivos y mantuvo niveles similares hasta mayo. En junio se llevó a cabo un nuevo incremento de la dimensión de la tropa, que alcanzó la cifra de los 140 efectivos. En ese sentido, en setiembre la tropa estaba compuesta por 238 efectivos, y continuó creciendo el resto de meses del año, pues en octubre se le asignó nuevamente la compañía de infantería que había sido suprimida a fines de 1836. ¿A qué se debió el constante incremento de la fuerza policial de Lima a partir de enero de 1837? La creación de la Confederación PerúBoliviana en octubre de 1836, bajo la dirección de Andrés de Santa Cruz, provocó reacciones hostiles de países extranjeros, principalmente de Chile y Argentina. En ese sentido, Chile le declaró la guerra a la confederación a fines de 1836 (Basadre, 2015, tomo 2, p. 131). En consecuencia, existía la posibilidad de que fuerzas militares chilenas desembarcasen en un punto de la costa cercano a la ciudad capital. Por ello, era necesario que se llevara a cabo un fortalecimiento de la fuerza policial del departamento de Lima no solo para garantizar la seguridad de la población, sino también el fortalecimiento de la fuerza militar desplegada en el departamento. Además, un factor que permitió el fortalecimiento de la fuerza policial de Lima fue la mejora de la situación de la hacienda pública. De acuerdo con los estimados de Bruno Seminario, en 1837 no se registró déficit fiscal, lo cual no ocurría desde 1828 (Seminario, 2015, p. 825).

El desembarco de las fuerzas militares chilenas se llevó a cabo en el sur del Perú en setiembre de 1837. Sin embargo, esta expedición fracasó, y provocó que Chile y la confederación firmaran el tratado de Paucarpata. La aparente paz generada por la firma de este tratado motivó que Santa Cruz, a fines de 1837, ordenase la reducción del ejército de la confederación (Aljovín y Lupú, 2018, p. 235). En ese sentido, en enero de 1838 se redujo el número de efectivos de la tropa de la fuerza policial de Lima a un nivel que se mantuvo constante hasta marzo. No fue una reducción drástica. En la tabla 2 se indica que la tropa seguía manteniendo más de 200 efectivos. Esto demuestra que el combate naval de Islay, desarrollado a inicios de 1838 entre las fuerzas navales confederada y chilena, puso en estado de alerta al gobierno de Santa Cruz. La inminencia de una nueva invasión chilena provocó que Santa Cruz decretara el incremento del ejército en febrero (Aljovín y Lupú, 2018, p. 236). La fuerza policial de Lima no fue ajena a esta política, ya que a partir de marzo sus dimensiones crecieron sostenidamente, hasta llegar en julio a estar integrada por 367 efectivos. 
Finalmente, la llamada segunda expedición restauradora desembarcó en la costa cercana a Lima en agosto de 1838 . Su avance hacia la ciudad capital originó la batalla de Portada de Guía, que se desarrolló en las inmediaciones de las murallas de la ciudad, y que finalizó con la victoria del ejército restaurador. En esta batalla participó el escuadrón de policía, cuyos sobrevivientes huyeron del campo de batalla ante la inminente derrota, de acuerdo con el testimonio del general Domingo Nieto (McEvoy, 2015, pp. 430-431). Es probable que la infantería de policía también participara en la mencionada batalla, y que lo que quedara de ella se retirara a otra localidad, como ocurrió con los efectivos sobrevivientes.

La victoria del ejército restaurador en la batalla de Portada de Guía provocó que tomara el control de la ciudad capital. Esta se encontraba desguarnecida, lo que generó que el ejército restaurador llevara a cabo algunos saqueos (Vargas Ugarte, 1971, pp. 200-201). Ahora bien, en cuanto al periodo que duró la estadía del ejército restaurador en la ciudad capital, solo hemos hallado evidencia acerca de una fuerza policial que estuvo compuesta por 69 efectivos en setiembre, como se muestra en la tabla 2. Además, es pertinente aclarar que las fuerzas restauradoras solo tenían el control político de la ciudad y localidades aledañas como Miraflores y Chorrillos. En el resto del departamento los montoneros aliados a la confederación habían tomado el control de los caminos cercanos a la ciudad, y los oficiales confederados y sus tropas se habían replegado a provincias como Canta (Vargas Ugarte, 1971, pp. 204-207).

El ejército restaurador decidió abandonar la ciudad y retirarse a la sierra central en noviembre de 1838, lo que provocó el ingreso del ejército confederado a la ciudad (Basadre, 2015, tomo 2, p. 143). En este mes y en diciembre se formó una fuerza policial compuesta por 50 y 59 hombres, respectivamente, como se muestra en la tabla 2 . La razón de la formación de esta reducida fuerza policial es clara: para Santa Cruz y sus oficiales la prioridad era reforzar a las compañías militares que iban a iniciar la persecución del ejército restaurador. No obstante, la derrota del ejército confederado en la batalla de Yungay, a inicios de 1839, representó la estocada final al proyecto político de la Confederación Perú-Boliviana. Las guerras que propiciaron su nacimiento, así como la que originó su caída, afectaron considerablemente la formación de las fuerzas policiales de Lima.

\section{Conclusiones}

La fundación de la fuerza policial del Ejército en el departamento de Lima fue una medida que buscó reforzar la protección de la seguridad pública, con el fin de legitimar la autoridad del naciente Estado peruano. En ese sentido, los cambios en la normatividad sobre dicha fuerza policial 
evidencian intentos de adaptar su estructura a la recurrente inestabilidad política que marcó la temprana república peruana. Por ejemplo, la fundación de la infantería de policía en 1834 y su reactivación a fines de 1837, después de su supresión en el año anterior, demuestran que se buscaba reforzar la presencia policial al interior de la ciudad capital para disuadir el ingreso a su interior de grupos de montoneros y de ejércitos extranjeros en contextos bélicos.

Sin embargo, la estructura de las fuerzas policiales del Ejército fue socavada por la dinámica bélica. Al ser porosa la estructura de las compañías que integraban el Ejército, se podía debilitar o suprimir a las dichas fuerzas policiales para propiciar su traslado a otras unidades militares. Si bien la guerra contra la Gran Colombia en 1828 redujo mínimamente la dimensión del escuadrón de policía, fue un anuncio de lo que podía llegar a pasar en el futuro. En efecto, las guerras civiles de 1834 y 1835 generaron la disolución momentánea de la fuerza policial del Ejército, debido a que la precariedad del Ejército, reducido considerablemente en años anteriores, fue agravada por su división en bandos enfrentados entre sí y por la dinámica bélica. Por ello, Orbegoso y Salaverry, los caudillos que controlaron políticamente Lima, en 1834 y 1835, decidieron incorporar los efectivos policiales a las compañías militares de sus ejércitos, que se alistaban a marchar al campo de batalla. A fines de 1835 la supresión de la fuerza policial que se encontraba dentro de la ciudad tuvo consecuencias dramáticas. Grupos de montoneros entraron a Lima y sembraron el caos algunos días.

El contexto de 1838 fue distinto al de 1834 y 1835 . Hay que tener en cuenta que desde 1837 se estaba llevando a cabo un considerable incremento del ejército y de su fuerza policial. Este fortalecimiento obedecía a la presunción de una invasión extranjera a la costa cercana a la ciudad capital. Cuando la invasión se produjo a mediados de 1838, los efectivos policiales fueron incorporados el ejército confederado. La derrota de este ejército en la batalla de Portada de Guía generó la disolución de la fuerza policial. Su posterior restablecimiento se llevó a cabo con una dimensión mucho menor a la que había tenido anteriormente como consecuencia de que la guerra ya había entrado en una fase definitoria, para lo cual era necesario fortalecer al ejército confederado.

Finalmente, resulta pertinente relacionar nuestros hallazgos con el modelo de formación de los Estados europeos acuñado por Charles Tilly. Para este autor, las guerras generaron el fortalecimiento de los Estados europeos, principalmente desde el siglo XVIII. En otras palabras, las guerras, al exigir el fortalecimiento constante de los ejércitos, provocaron el desarrollo y la sofisticación de métodos de extracción de recursos de la 
sociedad por parte de los Estados (Tilly, 1992, pp. 48-53). Sin embargo, al priorizar Tilly una visión de larga duración, descuida el impacto coyuntural que pudieron tener las guerras en las regiones en las que se desarrollaron. En ese sentido, una guerra europea del siglo XIX pudo haber provocado el uso militar de las fuerzas policiales, como ocurrió en Lima durante la temprana república. En suma, así como es pertinente tener una visión transnacional y de larga duración de los procesos de formación de los Estados, como la de Tilly, también es necesario tener una visión mucho más focalizada para entender toda la complejidad de dichos procesos históricos.

\section{Contribución del autor}

Carlos Jesús Ríos Rodríguez ha participado en la concepción, la recolección de datos, la redacción y la aprobación de la versión final del artículo.

\section{Fuente de financiamiento}

Autofinanciado.

\section{Conflictos de interés}

El autor declara no tener conflictos de interés. 


\section{ANEXO}

DENOMINACIONES DE LAS FUERZAS POLICIALES DEL EJÉRCITO (1825-1838)

\begin{tabular}{lc}
\hline Denominación & Periodo \\
\hline Escuadrón de Dragones de Policía & $1825-1829$ \\
\hline Compañía de Seguridad Pública & $1829-1834$ \\
\hline Cuerpo de Policía & $1834-1835$ \\
\hline Escuadrón de Gendarmes & 1835 \\
\hline Escuadrón de Dragones de Lima & 1835 \\
\hline Cuerpo de Policía & 1836 \\
\hline Escuadrón de Policía & $1836-1837$ \\
\hline Cuerpo de Policía & $1837-1838$ \\
\hline Fuente: Elaboración propia &
\end{tabular}

\section{FUENTES DE ARCHIVO}

Archivo General de la Nación (AGN): Ministerio de Hacienda, expedientes oficiales (O. L.).

Archivo Histórico Militar (AHM): correspondencia recibida por el Ministerio de Guerra. 


\section{REFERENCIAS BIBLIOGRÁFICAS}

Aljovín, C. (2000). Caudillos y Constituciones. Perú: 1821-1845. Lima: Instituto Riva-Agüero y Fondo de Cultura Económica.

Aljovín, C. y Lupú, J. C. (2018). Ejército, Estado y Nación en tiempos de la Confederación Perú-Boliviana. En C. McEvoy y A. Rabinovich (Eds.), Tiempo de guerra. Estado, nación y conflicto armado en el Perú, siglos XVII-XIX (pp. 215-248). Lima: Instituto de Estudios Peruanos.

Basadre, J. (2015). Historia de la República del Perú. Tomos 1 y 2. Lima: El Comercio.

Contreras, C. (2012). La economía pública en el Perú después del guano y del salitre. Crisis fiscal y élites económicas durante su primer siglo independiente. Lima: Instituto de Estudios Peruanos.

Echenique, J. R. (1952). Memorias para la historia del Perú (1808-1878). Tomo 1. Lima: Huascarán.

Gootenberg, P. (1997). Caudillos y comerciantes. La formación económica del Estado peruano. Cusco: Centro Bartolomé de las Casas.

Mackenney, R. (1996). La Europa del siglo XVI. Expansión y conflicto. Madrid: Akal.

McEvoy, C. (2015). La guerra maldita. Domingo Nieto y su correspondencia (1834-1844). Tomo 1. Lima: Biblioteca Nacional del Perú.

Medina, L. (1989). EI Ejército en la república: siglo XIX. La institucionalización del Ejército: logística. Lima: Comisión Permanente de Historia del Ejército del Perú.

Méndez, C. (2013). La guerra que no cesa: Guerras civiles, imaginario nacional y la formación del Estado en el Perú. En C. Thibaud, G. Entin, A. Gómez y F. Morelli (Eds.), L'Atlantique Révolutionnaire. Une perspective IberoAméricaine (pp. 379-420). Bécherel: Éditions Les Perséides.

Merino Arana, R. (1966). Historia policial del Perú en la República. Lima: Departamento de Prensa y Publicaciones de la Guardia Civil.

Oviedo, J. (1861). Colección de leyes, decretos y órdenes publicadas en el Perú desde el año de 1821 hasta 31 de diciembre de 1859. Tomos 2, 3, 6 y 13. Lima: Felipe Bailly.

Palma Alvarado, D. (2016). Los cuerpos de serenos y el origen de las modernas funciones policiales en Chile (siglo XIX). Historia, 49(2), pp. 509-545.

Piérola, N. de (1827). Calendario y guía de forasteros de Lima para el año bisiesto de 1828. Lima: Imprenta de la Instrucción Primaria.

Pulido Esteva, D. (2017). Después del alcalde de barrio: experiencias policiales en la Ciudad de México (1824-1861). Nuevo Mundo. Mundos Nuevos, 17. Recuperado de http://journals.openedition.org/nuevomundo/70578 
República del Perú (1823). Constitución de 1823. Recuperado de http:// www.leyes.congreso.gob.pe/Documentos/constituciones_ordenado/ CONSTIT_1823/Cons1823_TEXTO.pdf/

República del Perú (1826). Constitución de 1826. Recuperado de http:// www.leyes.congreso.gob.pe/Documentos/constituciones_ordenado/ CONSTIT_1826/Cons1826_TEXTO.pdf

República del Perú (1828). Constitución de 1828. Recuperado de http:// www.leyes.congreso.gob.pe/Documentos/constituciones_ordenado/ CONSTIT_1828/Cons1828_TEXTO.pdf/

República del Perú (1834). Constitución de 1834. Recuperado de http:// www.leyes.congreso.gob.pe/Documentos/constituciones_ordenado/ CONSTIT_1834/Cons1834_TEXTO.pdf/

Ríos Rodríguez, C. (2018). La seguridad pública de Lima y la formación del Estado peruano (1825-1855) (tesis de magíster en Historia). Universidad Nacional Mayor de San Marcos, Lima.

Seminario, B. (2015). El desarrollo de la economía peruana en la era moderna. Precios, población, demanda y producción desde 1700. Lima: Universidad del Pacífico.

Tilly, C. (1992). Coerción, capital y los Estados europeos, 990-1990. Madrid: Alianza Editorial.

Vargas Ugarte, R. (1971). Historia general del Perú. Tomo. 8. Lima: Milla Batres.

Velásquez Silva, D. (2013). La reforma militar y el gobierno de Nicolás de Piérola. El Ejército moderno y la construcción del Estado peruano (tesis de magíster en Historia). Universidad Nacional Mayor de San Marcos, Lima.

Von Tschudi, Johann (1966) [1846]. Testimonio del Perú, 1838-1842. Lima: Talleres Gráficos. P. L. Villanueva.

Walker, C. (1990). Montoneros, bandoleros, malhechores: criminalidad y política en las primeras décadas republicanas. En C. Aguirre y $C$. Walker (Eds.), Bandoleros, abigeos y montoneros. Criminalidad y violencia en el Perú, siglos XVIII-XX (pp. 105-136). Lima: Instituto de Apoyo Agrario.

Weber,M.(2002).Economíaysociedad.Madrid:FondodeCulturaEconómica. Zapata Cesti, V. (1949). Historia de la policía del Perú. Lima: s. d. 